\title{
Psychological Adjustment to Success and to Failure following Epilepsy Surgery
}

\author{
Paul A. Derry and Samuel Wiebe
}

\begin{abstract}
Treatment-refractory epilepsy can directly impair psychological adjustment and quality of life. Epilepsy surgery is viewed by the patient as a stressful life event, arrived at after extensive deliberation. It is accompanied by expectations and anxiety for patients and their families. We suggest that the success of epilepsy surgery (as reflected by patient-perceived impact on quality of life) depends not only on reduced seizure frequency, but on personality factors and psychosocial issues. This paper reviews our research on these factors, along with suggestions for psychological assessment (of quality of life, and of personality) and psychological treatment. Studies of quality of life in patients undergoing temporal lobectomy are also examined. Finally, factors leading to the perception of "failed" epilepsy surgery are considered, along with suggested ways to manage such cases.
\end{abstract}

RÉSUMÉ: Ajustement psychologique au succès et à l'échec après la chirurgie de l'épilepsie. L'épilepsie réfractaire au traitement peut compromettre directement l'ajustement psychologique et la qualité de vie. La chirurgie de l'épilepsie est considérée par le patient comme un événement stressant de la vie, qui est décidé après de longues délibérations et qui est accompagné d'attentes et d'anxiété de la part des patients et de leur famille. Nous suggérons que le succès de la chirurgie de l'épilepsie, tel que reflété par l'impact sur la qualité de vie perçue par le patient, dépend non seulement d'une diminution de la fréquence des crises mais aussi de facteurs de la personnalité et de questions psychosociales. Cet article revoit nos recherches sur ces facteurs fournit des suggestions pour l'évaluation psychologique de la qualité de vie et de la personnalité et pour le traitement psychologique. Nous examinons les études sur la qualité de vie chez les patients qui subissent une lobectomie temporale. Finalement, nous discutons des facteurs conduisant à la perception que la chirurgie de l'épilepsie a été un échec ainsi que des façons de gérer ces cas.

Can. J. Neurol. Sci. 2000; 27: Suppl. 1 - S116-S120

It has long been recognized that chronic treatment-refractory epilepsy can directly impair psychological adjustment and quality of life (QOL). ${ }^{1}$ Problems may be evident in emotional and interpersonal adjustment, educational and vocational achievement, and self-esteem. ${ }^{2-8}$ Epilepsy surgery is viewed by the patient as a stressful event, arrived at after considerable investment of time and energy. It holds expectations and anxiety for patients and their families. The variety of responses to this important life event depend in part on psychological factors. This article discusses these issues, along with suggestions for assessment and psychological intervention. Rather than presenting an exhaustive literature review, we offer a position paper on key aspects of psychological adjustment and quality of life as they pertain to temporal lobectomy for the treatment of epilepsy.

\section{FACtORS AFFECTING PSYCHOLOGICAL ADJUSTMENT}

\section{Psychological adjustment}

Temporal lobectomy is an effective treatment for patients with medically intractable temporal lobe epilepsy. ${ }^{9-13}$ Although temporal lobectomy is a neurosurgical procedure, it engenders a range of psychological reactions. Adjustment, viewed as a psychological process, refers to how one copes with demands and challenges. Adjustment is not an endpoint but a process requiring coping efforts, some leading to more positive outcomes than others. As patients frequently undergo temporal lobectomy with neurolept analgesia, ${ }^{14}$ and because they are cognizant of the risks of brain surgery, ${ }^{15}$ the procedure is viewed as stressful by the patient and the family. Stress researchers postulate that an event is stressful because it is appraised as being harmful or threatening. ${ }^{16}$ This model of stress places emphasis on subjective appraisal, and explains why some people view an event as stressful while others do not.

From the Departments of Psychological Services (P.A.D.) and Clinical Neurologica Sciences (P.A.D., S.W.), London Health Sciences Centre, University Campus, University of Western Ontario, London, ON, Canada

Reprint requests to: P. Derry, Epilepsy Unit and Department of Psychological Services, London Health Sciences Centre, University Campus, 339 Windermere Road, London, Ontario, Canada N6A5A5 


\section{Factors influencing psychological adjustment to epilepsy surgery}

Research has identified factors about the person that influence health outcomes in medical settings. ${ }^{17}$ An important one is personality style, such as hardiness ${ }^{18}$ and optimism. ${ }^{19}$. We found that learned resourcefulness (taking personal responsibility for managing one's health) is associated with good psychosocial adjustment following temporal lobectomy. ${ }^{20} \mathrm{~A}$ second factor influencing coping with stressful events is a history of successful adjustment to similar circumstances. Better overall preoperative psychological adjustment (including absence of a psychological/ psychiatric history, and positive self-perceived QOL) tends to predict favourable adjustment to medical treatments. ${ }^{21-28}$ Third, a broad range of available coping behaviors is generally associated with more favourable adjustment; ${ }^{16}$ active and confrontative coping is generally more effective than avoidant strategies, and is associated with better physical and emotional health. ${ }^{16,17}$ Thus, a patient's typical manner of coping with stressful situations should influence psychological adjustment to temporal lobectomy. Fourth, patient expectations have considerable impact on post-surgical acceptance of outcome. If they are unrealistic, various negative outcomes are possible. ${ }^{29}$ Finally, the availability of social support strongly influences successful coping because of its buffering effect against the negative effects of stress. ${ }^{30}$

\section{PSYChOLOGICAL ASSESSMENT}

\section{When to assess}

In our view, evaluation of the patient's adjustment to temporal lobectomy should include a baseline assessment before surgery, and again at several points in postoperative follow-up. The most comprehensive and detailed evaluations are conducted at baseline and two-year follow-up; selected assessments are administered at interim intervals. The minimum comprehensive assessment should evaluate the history, mental status, mood, personality, ways of coping with stress, and self-perceived quality of life. These measures are described in greater detail in a subsequent section. Interim assessments prior to the two-year follow-up should evaluate mood (depression and anxiety scales are typically responsive to changes, and can be repeatedly administered); in addition, changes in memory, language, and psychosocial functioning should be noted.

There are compelling reasons for multiple follow-up evaluations. Assessment in the days following surgery can identify problems such as psychosis and mood disturbance. Objective signs of newly-developed depression and anxiety have been found as soon as six weeks following surgery, ${ }^{29}$ and we have seen cases of postoperative hypomania. Others have reported depression at six months ${ }^{31}$ and one year. ${ }^{32}$ In a prospective series of temporal lobectomy cases, McLachlan et $\mathrm{al}^{1}$ found that improved patient-perceived quality of life was often not seen until two years following surgery. Therefore, follow-up should include interim assessments before discharge and again at six weeks and six months, followed by more detailed and comprehensive evaluations at one and two years.

\section{Assessment methodology}

Interviews of patients and collaterals (family or friends), combined with psychometrically sound test data, yield a comprehensive and reliable portrayal of psychological adjustment. Repeated measures over time can detect changes. Seeking to avoid overlap with other professionals simultaneously studying the patient, psychological and QOL evaluation should begin with a history. This history includes the patient's psychological history, psychosocial development, early family environment (including reaction of the family to the seizure disorder), family history of psychopathology, outcome of previous attempts to cope with stressful situations, attitudes toward medical interventions, occupational and educational history, interpersonal relationships, and functional history (e.g., driving). Next, inquiry into current psychological function should address mental status (including ability to provide informed consent), mood and affect, cognition, interpersonal interactions, availability of social support, personality, selfperceived QOL (as assessed broadly, and also in specific domains of functioning), and habitual ways of coping with stress. Pre-operative expectations of surgery must be evaluated. ${ }^{29}$ The concordance between physician-communicated and patientperceived expectations should be ascertained, and one would wish to establish that the family's expectations are realistic.

Objective and quantifiable data are of greatest value for answering empirical questions. Besides quasi-structured clinical/diagnostic interviews, we advocate the administration of standardized and objective psychological tests. ${ }^{33}$ Minimizing response burden to patients should be a goal in selecting the assessment battery, along with identifying tests that have demonstrated sensitivity, specificity, and responsiveness to change. ${ }^{24,34}$

\section{(a) Personality}

A clinically valuable portrayal of personality is obtained from the MMPI-2. ${ }^{35}$ MMPI-2 scores tend not to be spuriously inflated because of reporting seizure symptoms $\mathrm{s}^{35}$ and are of particular value in identifying patients with pseudoseizures. ${ }^{36}$ Objective psychological assessment of conversion disorder and pseudoseizures can considerably assist the physician's diagnosis of pseudoseizures.

\section{(b) Other standardized measures: quality of life}

Quality of life in epilepsy is considered in detail in another article in this series. The ESI-55 $5^{37}$ and the closely related QOLIE- $89^{38}$ provide a good portrayal of epilepsy-relevant quality of life, with acceptable reliability. The clinician is often interested in evaluating changes in patient function, and these are good instruments for that purpose. ${ }^{34}$ Mood can be quickly and reliably evaluated using the Beck Depression Inventory or the Centre for Epidemiological Studies Depression Scale (CES-D) ${ }^{39}$ (both evaluating depression), and the State-Trait Anxiety Inventory ${ }^{40}$ for anxiety. Subtests of the Symptom Checklist-90Revised (SCL-90-R) ${ }^{41}$ provide estimates of particular emotional and behavioral problems, and are sensitive to change. ${ }^{34}$ Coping style can be evaluated with the Ways of Coping questionnaire, ${ }^{42}$ a widely used measure in stress research and outcome studies.

\section{(c) Other measures}

Some psychologists use the Washington Psychosocial Seizure Inventory (WPSI). ${ }^{43}$ In one study we found it relatively insensitive to change, ${ }^{34}$ in contrast to the SCL-90- $\mathrm{R}^{41}$ which demonstrated good responsiveness in an epilepsy surgery population. ${ }^{34} \mathrm{~A}$ measure of family interactions can be provided 
by the Family Environment Scale ${ }^{44}$ and neuroticism can be reliably evaluated. ${ }^{45,46}$ Formal assessment and documentation of patient expectations of surgery are strongly recommended. Structured Likert-type ratings have merit because they provide an objective record. Such ratings could be developed by creating a checklist of typical surgical outcomes, then having the physician rate the likelihood of each outcome for a given patient. The patient would then rate how strongly each outcome is anticipated. This brief instrument would yield data on "realistic" outcomes, would document what the patient expects, and would ensure discrepant expectations have been addressed before surgery.

\section{EVIDENCE REGARDING PSYCHOLOGICAL ADJUSTMENT}

We conducted a prospective evaluation of outcome in our epilepsy patients undergoing either temporal lobectomy or medical management. ${ }^{1}$ Seizure frequency and quality of life were assessed before and 6, 12, and 24 months after treatment. As expected for operated patients, seizure outcome was significantly better at all outcome assessments. At 24 months, seizure-free patients and those with at least $90 \%$ reduction in seizure frequency reported significant improvements in healthrelated quality of life. Deterioration in quality of life occurred with less than $90 \%$ seizure reduction. This study was notable in that it was the first long-term prospectively-designed follow-up comparison of surgical with nonsurgical patients. It was also noteworthy for its emphasis on quality of life. Changes in QOL may not be evident until a full two years following surgery, ${ }^{1}$ which is why we suggest waiting that long before evaluating this aspect of outcome.

Our research has endeavoured to empirically identify preoperative predictors of favourable psychological outcome following temporal lobectomy. The data ${ }^{1}$ suggest that best quality of life outcomes and improvements are evident in seizure-free patients and those with at least $90 \%$ improvement. However, seizure-free status is not the only predictor of favourable selfperceived quality of life. Our data suggest the following areas of function, when evaluated before surgery, account for a significant amount of variability in psychological adjustment one to two years following temporal lobectomy. These factors include attributional style ${ }^{47}$ (perceiving the cause of one's seizures as lying within vs. beyond personal control), a personality style termed learned resourcefulness ${ }^{20}$ (taking active responsibility for one's health), and neuroticism ${ }^{46}$ (a broad personality trait involving anxiety and hostility). Also, preoperative emotional distress (including preoperative depression) is a statistically strong predictor of depression two years after temporal lobectomy. ${ }^{48}$ Taken together, these studies suggest that postoperative QOL and psychological adjustment is not merely a function of seizure-free status; it is also considerably influenced by enduring and measurable personality variables.

Reports from other centres, although largely retrospective, generally agree with these findings, and are typically measured at six months ${ }^{31}$ or one year following temporal lobectomy. ${ }^{25-28,49}$

\section{FACILITATING POSTOPERATIVE ADJUSTMENT}

Because temporal lobectomy is a highly significant event to patients, they typically experience the need to talk about it.
Along with friends and family, postsurgical support groups provide an important venue for this need. In addition, members of the health-care team should be available to answer questions and provide reassurance. Individual psychotherapy, typically brief and problem-focused, may be indicated in some cases.

\section{Adjustment to Failure}

Failed temporal lobectomy could narrowly be defined as not achieving a seizure-free outcome. However, this does not reflect the variety of reasons why the procedure is performed, and ignores differences in expectations. To reduce the seizure frequency by a half, or to eliminate one of two seizure types while leaving the other unchanged, could be seen as favourable outcomes if they had been agreed-upon goals prior to surgery. "Failure" is a judgment based on preoperative expectations. Specifically discussing expectations before surgery obviates the need to deal with perceptions of failure in most cases. To illustrate, the patient and physician might agree before surgery that available clinical data suggest a goal of $80 \%$ seizure reduction on one medication rather than two. Here, expectations are clear and realistic. If the patient does not become seizurefree, but the goal is met, then success (rather than failure) would be perceived.

On occasion, seizure frequency is unchanged following surgery. In such cases, patients need information and counselling to assist their appraisal of this outcome in the most realistic light. Where surgery has not produced the anticipated benefit, individuals may continue to experience psychosocial and economic problems such as barriers to employment opportunities, reduced income potential, continued societal misunderstanding, coping with medication side-effects, and restrictions on driving. Psychotherapy and support groups, along with continued medical management, are important in these cases.

\section{SUMMARY AND DIRECTIONS}

Good seizure control that usually occurs after temporal lobectomy is associated with favourable quality of life indicators. ${ }^{1}$ Positive psychological outcomes are not uniquely a function of seizure reduction. Pre-operative factors such as

(a)favourable psychological adjustment,

(b)good self-perceived QOL,

(c)being low on the trait of neuroticism,

(d)the tendency toward learned resourcefulness, and

(e) having adequate available social support, all increase the chances of positive surgical outcomes. Persons who have been employed (or who are students) will likely continue to be so after surgery.

Less favourable prognostic signs are essentially the converse of the above. They include

(a)considerable psychological distress,

(b)displaying an anxious disposition characterized as neuroticism,

(c)a helpless attitude toward self-management of health,

(d rigidly unrealistic expectations, and

(e) poor interpersonal interactions with the physician (e.g., hostility). 


\section{Psychological treatment}

Where preoperative assessment suggests the likelihood of postoperative adjustment problems, psychological intervention should be planned. Such circumstances respond well to a combination of physician advice and brief psychological treatment. Social support is facilitated by outpatient support groups.

\section{Multicentre research}

While the choice of psychological tests is guided by the unique needs of an epilepsy service, Canadian researchers would be well advised to work toward common measures that would constitute the core of a national epilepsy database. The currently operational CEDaR database ${ }^{50}$ could be expanded to incorporate a quality of life section. All Canadian epilepsy treatment centres could contribute objective, quantifiable data which in turn would be accessible to all participants. Flexibility would permit individual researchers to add research variables of interest to them. Being able to conduct large sample multi-centre studies will allow us to answer important questions in epilepsy. Conclusions based on such a large database would also add to physicians' and patients' confidence when making treatment decisions.

\section{ACKNOWLEDGEMENTS}

Dr. R.S. McLachlan is acknowledged for his on-going support of some of the research discussed in this article. We thank Dr. W.T. Blume, Dr. J.P. Girvin, Dr. A.G. Parrent, and Dr. R. Sahjpaul for access to data on their patients.

\section{REFERENCES}

1. McLachlan RS, Rose KJ, Derry PA,et al. Health-related quality of life and seizure control in temporal lobe epilepsy. Ann Neurol 1997;41:482-489.

2. Cramer JA. Quality of life for people with epilepsy. Neurol Clin 1994;12:1-13

3. Jacoby A. Epilepsy and the quality of everyday life: findings from a study of people with well-controlled epilepsy. Soc Sci Med 1992;34:657-666.

4. Hermann B. Quality of life in epilepsy. J Epilepsy 1992;5:153-165.

5. Antonak RF, Livneh $\mathrm{H}$. A review of research on psychosocial adjustment to impairment among persons with epilepsy. J Epilepsy 1992;5:194-205.

6. Dodrill CB. Cognitive and psychosocial effects of epilepsy on adults. In: Wyllie E, ed. The Treatment of Epilepsy: Principles and Practices. Philadelphia: Lea \& Febiger, 1993:1133-1140.

7. Levin R, Banks S, Berg B. Psychosocial dimensions of epilepsy: a review of the literature. Epilepsia 1982:23;671-681.

8. Surgery for Epilepsy. NIH Consensus Statement. 1990 Mar 19-21; 8(2):1-20.

9. Engel J Jr, VanNess PC, Rasmussen TB, Ojemann LM. Outcome with respect to epileptic seizures. In: Engel $\mathrm{J} \mathrm{Jr}$, ed. Surgical Treatment of the Epilepsies. New York: Raven Press, 1993:609621.

10. Spencer DD \& Inserni J. Temporal lobectomy. In: Luders HO, ed. Epilepsy Surgery. New York: Raven Press, 1991:533-545.

11. Spencer SS. Long-term outcome after epilepsy surgery. Epilepsia 1996;37:807-813.

12. McLachlan RS, Chovaz CJ, Blume WT, Girvin JP. Temporal lobectomy for intractable epilepsy in patients over age 45 years. Neurology. 1992 Mar; 42 (3 Pt 1): 662-665.

13. Duchowny M, Levin B, Jayakar P, Resnick T,et al. Temporal lobectomy in early childhood. Epilepsia 1992;33(2):298-303.

14. Girvin JP. Resection of intracranial lesions under local anesthesia. Int Anesthesiol Clin 1986;24:135-155.
15. Blume WT. Principles of clinical investigation of surgical patients. Int Anesthesiol Clin 1986;24:47-63.

16. Lazarus RS, Folkman S. Stress, Appraisal and Coping. New York: Springer, 1984.

17. Taylor S. Health Psychology, 5th ed. New York: McGraw-Hill, 1995.

18. Kobassa SC. Stressful life events, personality, and health: an inquiry into hardiness. J Pers Soc Psychol 1979;37:1-11.

19. Scheier MF, Carver CS. Effects of optimism on psychological and physical well-being: theoretical overview and empirical update. Cog Theory Res 1992;16:201-228.

20. Derry PA, Chovaz C, McLachlan RS, Cummings AL. Learned resourcefulness and psychosocial adjustment following temporal lobectomy in epilepsy. J Soc Clin Psychol 1993;12:454-470.

21. Vickrey BG, Hays RD, Engel J. Jr, et al. Outcome assessment for epilepsy surgery: the impact of measuring health-related quality of life. Ann Neurol 1995;37:158-166.

22. Vickrey BG, Hays RD, Rausch R, et al. Outcomes in 248 patients who had diagnostic evaluations for epilepsy surgery. Lancet 1995;346:1445-1449.

23. Hermann BP, Wyler AR, Somes G. Preoperative psychological adjustment and surgical outcome are determinants of psychosocial status after anterior temporal lobectomy. J Neurol Neurosurg Psychiatry 1992;55:491-496.

24. Rose KJ, Derry PA, Wiebe S, McLachlan RS. Determinants of health-related quality of life after temporal lobe epilepsy surgery. Qual Life Res 1996;5:395-402.

25. Hermann BP, Wyler A, Somes G. Emotional and psychosocial outcome of anterotemporal lobectomy. Epilepsia 1989;30:738-739.

26. Batzel LW, Dodrill CB, Ojemann GA, et al. Psychological change is a function of seizure relief following resection surgery for epilepsy. Epilepsia 1991;32:30-31.

27. Hermann BP, Wyler AR, Somes G. Preoperative psychological adjustment and surgical outcome are determinants of psychosocial status after anterior temporal lobectomy. J Neurol Neurosurg Psychiatry 1992;55(6):491-496.

28. Kellett M, Smith D, Baker D, Chadwick D. Quality of life after epilepsy surgery. J Neurol Neurosurg Psychiatry 1997;63:52-58.

29. Rose KJ, Derry PA, McLachlan RS. Patient expectations and postoperative depression, anxiety, and psychosocial adjustment after temporal lobectomy: a prospective study. Int J Beh Med 1995;2:27-40.

30. Pennebaker JW, Kiecolt-Glaser JK, Glaser R. Disclosure of traumas and immune function: health implications for psychotherapy. J Consul Clin Psychol 1988;56:239-245.

31. Hermann BP, Wyler AR, Ackerman B, Rosenthal T. Short-term psychological outcome of anterior temporal lobectomy. J Neurosurg 1989;71:327-334.

32. Vickrey BG, Hays RD, Hermann BP, Bladin P, Batzel L. Outcomes with respect to quality of life. In: Engel $\mathrm{J} \mathrm{Jr}$, ed. Surgical Treatment of the Epilepsies, 2nd ed. New York: Raven Press, 1993; 623-635.

33. Mischel W. Introduction to personality, 5th ed. Fort Worth: Guilford Press, 1990.

34. Wiebe S, Rose KJ, Derry PA, McLachlan RS. Outcome assessment in epilepsy: comparative responsiveness of quality of life and psychosocial instruments. Epilepsia 1997;38:430-438.

35. Derry PA, Harnadek MCS, McLachlan RS, Sontrop J. Influence of seizure content on interpreting psychopathology on the MMPI-2 in patients with epilepsy. J Clin Exper Neuropsychol 1997; 19:396-404.

36. Derry PA, McLachlan RS. The MMPI-2 as an adjunct to the diagnosis of pseudoseizures. Seizure 1996:5:35-40.

37. Vickrey BG, Hays RD, Graber J, et al. A health-related quality of life instrument for patients evaluated for epilepsy surgery. Med Care 1992;30:299-319.

38. Perrine KR A new quality of life inventory for epilepsy patients: interim results. Epilepsia 1993;34(S.4):S28-S33.

39. Radloff LS, Lock BZ. The community mental health assessment survey and the CES-D Scale. In: Weissman MM, Meyers, J, Ross, $\mathrm{CE}$, eds. Epidemiological Community Surveys. New York: Prodist, 1983. 
40. Spielberger CD, Gorsuch RL, Lushene RE. Manual for the statetrait anxiety inventory (self-evaluation questionnaire). Palo Alto: Consulting Psychologists Press, 1970.

41. Derogatis LR, Lipman RS, Covi L. The SCL-90: an outpatient psychiatric rating scale. Psychopharmacol Bull 1974;9:13-28.

42. Folkman S, Lazarus RS, Dunkel-Schetter C, DeLongis A, Gruen RJ. Dynamics of a stressful encounter: cognitive appraisal, coping, and encounter outcomes. J Pers Soc Psychol 1986;50: 992-1003.

43. Dodrill CB, Batzel LW, Queisser, HR, Temkin NR. An objective method for the assessment of psychological and social problems among epileptics. Epilepsia 1980;21:123-135.

44. Moos R, Moos B. Family Environment Scale manual. Palo Alto: Consulting Psychologists Press, 1981.

45. Watson D, Clark L. On traits and temperament: general and specific factors of emotional experience and their relation to the fivefactor model. J Pers 1992;60:441-476.

46. Rose KJ, Derry PA, McLachlan RS. Neuroticism in temporal lobe epilepsy: assessment and implications for pre- and postoperative psychosocial adjustment and health-related quality of life. Epilepsia 1996:37:484-491.

47. Derry PA, McLachlan RS. Causal attributions for seizures: relation to preoperative psychological adjustment and postoperative psychosocial function in temporal lobe epilepsy. J Epilepsy 1995;8:74-82.

48. Derry PA, Rose KJ, McLachlan RS. Predicting depression following surgery for temporal lobe epilepsy: impact of preoperative emotional adjustment. Unpublished manuscript, University Hospital, 1997.

49. Hermann BP, Trenerry MR, Colligan RC, et al. Learned helplessness, attributional style, and depression in epilepsy. Epilepsia 1996;37:680-686.

50. McLachlan RS, Dooley J, Casbourn H. Canadian Epilepsy Database and Registry. 2nd International Congress of Epilepsy, Dublin, 1997. 